\title{
Uncertainty, power, institutions, and crisis: implications for economic analysis and the future of capitalism
}

\author{
Amitava Krishna Dutt ${ }^{*}$ \\ Professor of Economics and Political Science, Department of Political Science, University of Notre Dame, \\ IN, USA and Distinguished Professor, FLACSO, Quito, Ecuador
}

This paper argues that the recent global crisis has confirmed in a stark manner that the dominant mainstream approach to the study of economics is seriously deficient. While these deficiencies are multidimensional, a major reason is that the dominant approach fails to take into account seriously and adequately three major aspects of real-world economies: uncertainty, power, and institutions. Incorporating these issues into economic analysis, which is the urgent and important business at hand for critics of mainstream economics, leads to a more appropriate approach to policies that can help to shape more desirable forms of capitalism.

Keywords: economic crisis, financial crisis, uncertainty, power, institutions, neoclassical economics, political economy, heterodox macroeconomics

JEL codes: $B 50, B 41, E 60, E 02, P 16$

\section{INTRODUCTION}

The global financial and economic crisis of 2008, which reduced growth and even output, and increased unemployment in many parts of the world - and from which many economies are yet to emerge - has led to much discussion and debate on how capitalist economies, including the global economy, should be analysed, and how they should be reshaped by appropriate policies.

Regarding economic analysis, many observers - including some prominent mainstream economists - have been highly critical of standard mainstream economics for its general failure to recognize the onset of the crisis, let alone to precisely predict it. The criticisms of mainstream economics implicit in this indictment are not new. A large minority of economists and other social scientists - the present author included have for some time raised questions about many aspects of mainstream economics and tried to develop alternative ways of analysing the economy. However, there seems to be little agreement about how, if at all, economic analysis ought to change and whether it will actually do so. Moreover, while there are many critics both inside

* I am grateful to the participants of the XI International Colloquium, 6-7 May 2014 on 'Global Crisis and the Need for Paradigm Change' at the University of Brasilia (UnB), and of seminars at the University of Sao Paulo and the University of Minas Gerais, Belo Horizonte, Brazil, and to Panos Liossatos and Wilson Perez for useful comments and suggestions. I am also grateful to INET for financial support. 
and outside the discipline, many of those within it seem to be digging in their heels and becoming more entrenched in their standard mainstream views, ${ }^{1}$ while many of those outside it continue to treat mainstream economists as 'experts.'

Regarding economic policy, in the immediate aftermath of the crisis there was a retreat from the reigning doctrines of free market fundamentalism and conservative macroeconomic policy focused on inflation control, as reflected by attempts at the regulation of (and government intervention in) financial systems, and expansionary fiscal and monetary policies in various parts of the world, including the US. However, free market dogma, and fears of inflation and government debt and deficits, are now on their ascendancy.

The purpose of this paper is to reflect on the failures of mainstream economic analysis and policy, as revealed yet again by the crisis, and to argue the need for an alternative approach which implies a different vision of capitalism. It does so by examining three analytical concepts: uncertainty, power, and institutions.

Three caveats are required to clarify the scope of this paper before we go any further. First, no attempt will be made to examine the global financial crisis or its causes and effects in a systematic and detailed manner. Rather, it will discuss in broad terms some causes which are relevant for the critique of mainstream economic analysis and its implications. Second, given its relatively short length, the paper can only offer some broad-brush comments and generalizations, merely providing rough sketches of a critique of mainstream economic analysis and policy, and of preferable alternatives. Third, and related to the point just made, the paper does not develop new theories or provide new empirical analysis. Its claim to some degree of novelty is in discussing the three concepts mentioned above and in relating them to alternative approaches to economic analysis, policy, and visions of capitalism.

The rest of this paper proceeds as follows. Section 2 provides a brief account of the causes of the recent crisis, stressing that the crisis can be attributed not to a single cause, but to a variety of interacting factors. Section 3 provides a brief discussion of the nature of mainstream economics. Section 4 discusses the three key analytical concepts that have either been ignored or have not been analysed appropriately in mainstream economic theories, namely uncertainty, power, and institutions. Section 5 examines the implications for taking these into account for the nature of economic analysis and policy and the vision of capitalism. Section 6 concludes.

\section{THE CRISIS}

A great deal has been written about the causes of the recent financial and economic crisis. Without going into a detailed discussion of these causes, or references to the many contributors to this literature, I would like to draw attention to three major economic factors which seem to have been extensively discussed.

The first factor is financial instability. It has been argued that financial markets are inherently unstable, that they alternate between periods of euphoria, in which people and organizations expand their activity and become more indebted with the expectation that the future will continue to be rosy at least for a while, and periods of crisis in which they reduce their level of economic activity, are unwilling to borrow and lend, and try to become more liquid (see Minsky 1982). This happens even though they may know that periods of euphoria and crisis will not last forever, as they do not

1. For an interpretation of this phenomenon, as well as its interaction with the story of neoliberalism, see Mirowski (2013). 
know precisely when they will end. Micro-macro interactions imply self-fulfilling prophecies, and price changes in response to excess supply and demand are often unlikely to bring stability to the financial sector. These trends have been exacerbated by financial 'innovations' involving the creation of new types of financial assets (for instance, derivatives such as mortgage-backed securities, collateralized debt obligations, and credit default swaps), the nature of monetary incentives in the form of compensation packages in the financial sector (which encouraged lending based on unrealized returns), by the absence or removal of government regulations to curb the instability (for instance, in the US, the repeal of the Glass-Steagall Act of 1933, which had prevented commercial banks from risky investment-financing activity, and the decision not to regulate the derivative markets), and by illegal and unethical behavior (sometimes referred to as 'greed') on the part of financial actors. All this was amplified by international capital flows which transmit financial problems across national borders.

The second factor involves macroeconomic imbalances, which have sometimes been referred to as imbalances between economic flow variables and between flow and stock variables. Imbalances in flows include those between the aggregate demand for goods and services and aggregate supply - that is, what can be produced by available resources and methods of production, an imbalance that reduces output and hence profitability, with a feedback effect on financial markets, especially stock markets. Imbalances between stocks and flows can occur in debt-income, debt-profit, and debt-GDP ratios of households, firms, and governments, respectively, and are likely to result in declines in components in aggregate demand (as a reaction to over-indebtedness) and also have direct and adverse financial market effects, affecting interest rates and credit availability. Imbalances can also occur in the foreign sector, for instance, in the current account deficit-GDP ratio and the external debt-GDP ratio of a country, which can result in government policy responses that can reduce aggregate demand and also fuel international financial instability.

The third factor is economic inequality, within and between countries. Inequality has been growing within many countries, as shown by declines in the share of labor in total income and by more dramatic changes in the personal distribution of income and the distribution of wage income. Inequality between countries remains high, and has been growing according to several measures, although for some less-developed countries, most notably China and also India, the gap with high-income countries, while large, has begun to narrow. The effect of changes in income distribution has affected both financial instability and the macroeconomic imbalances. Growing inequality in rich countries like the US has tended to reduce consumption demand and has contributed towards a decline in aggregate demand. In the US this has been counteracted by increasing indebtedness, especially among lower income groups, both as a result of efforts by them to maintain consumption in the face of stagnating income and because of the easier availability of credit due to the financial wealth of the rich and foreign borrowing. High levels of international inequality have resulted in trade imbalances, with some poorer countries with access to technology becoming internationally competitive compared to countries with high wages unless rich countries are able to develop technologically more sophisticated goods. Moreover, poor countries, given their fear of the effects of the volatility of international capital flows, have attempted to hold high levels of international reserves by running current account surpluses, whereas richer countries, which are less threatened by instability at least until recently - have not felt the same pressure and have often allowed increases in current account deficits by increasing spending to maintain aggregate demand and borrowing internationally. 
Three comments are worth making about these factors. First, it is difficult to choose which of these different factors is the most important necessary or sufficient condition for the crisis, since they are interrelated and operate in different ways, some due to recent changes in them and some as longer-term characteristics. For instance, high levels of inequality in rich countries, as noted earlier, have increased macroeconomic imbalances, by increasing debt-financed consumption in the face of stagnating income of many (as in the US), or high levels of net exports in some countries (like Germany), and rising inequality and macroeconomic imbalances have contributed to financial crises due to increases in debt and bubbles in asset prices, and due to the willingness of the rich to hold riskier assets with potentially higher yields. They are, in effect, three sides of a triangle. Although, in principle, economic problems can arise only in one or two sides (for instance, only in the financial sector, or due to the interaction between distribution and macro imbalances), the recent crisis seems to have involved all three.

Second, the three factors may be called economic ones in a narrow sense, and are related to broader cultural, social, and political factors which, together with the economic factors, can be called political economy factors. Thus, for instance, social factors related to changes in norms can explain a rise of unethical behavior, political factors involving greater ability of the financial sector to influence policymakers and legislators can explain financial deregulation, and political factors involving the greater clout of high-income groups and social and cultural factors which reduce the allegiance to community and increase the appeal of individualism can change government policies in ways that increase inequality. In turn, these broader factors are affected by changes in economic factors: for instance, rising inequality makes high-income groups and financial interests more politically influential. All of this implies that the economic factors need to be interpreted in a broader political economy context, and do not exhaust all the factors relevant for understanding the crisis.

Third, the factors point to some weaknesses in the nature of the economics profession which has not taken them into account adequately, a point that will be the subject of the next section. The failure is not one of failing to predict the crisis, since the job of economists should arguably not be to predict when something will happen, or what exactly will happen, but to understand what is happening, to provide warnings of what possibly looms ahead, and to recommend policies to avoid likely dangers. Moreover, it can be argued that the failure is not just regarding the crisis, but is related to a more general one of not properly understanding and responding to the major economic problems of our times, a deficiency which has been addressed by many critics. The crisis, however, has revealed the weaknesses in a dramatic way and has brought them onto the radar screen of a much larger group of people. The danger is that the appropriate lessons will not be learnt, or that, if they are learnt, they will soon be forgotten.

\section{NEOCLASSICAL ECONOMIC ANALYSIS}

This section will argue that the failure to understand and anticipate the crisis, and the support for policies that led to that crisis, can be laid largely at the door of some deficiencies of mainstream economics, or what can be called neoclassical economics. ${ }^{2}$

2. There has been some discussion of the differences between neoclassical, mainstream, and orthodox economics. For my purposes (and largely following Colander et al. 2004 and Dequech 2007-2008), I will refer to neoclassical economics in terms of its features or its characteristics. Mainstream economics will be referred to as a sociologically defined category, as the set of 
There is no widely-accepted definition of neoclassical economics. ${ }^{3}$ This is not surprising, because the social sciences, economics, and particular approaches to economics, involve a number of different dimensions. For the purposes of this paper I will focus on five dimensions, which can be called the ontological, epistemological, methodological, normative and prescriptive dimensions. ${ }^{4}$ By the ontological dimension I will refer to views on how the world actually is and how it works, at the level of individuals and groups who inhabit it, how they interact with each other, and how systems comprising them actually function. Since such views cannot incorporate all aspects of the real world, they involve abstraction and judgments about essential characteristics given the questions at hand. The epistemological dimension refers to what organizing principles are used in explaining and understanding the real world, features which are not actually properties of the real world, but which serve as the basis of organizing ideas about it. ${ }^{5}$ The methodological dimension refers

ideas (which need not be internally consistent in any sense) that happen to be held by 'individuals who are dominant in the leading academic institutions, organizations, and journals at any given time, especially the leading graduate research institutions' (Colander et al. 2004, p. 490), and 'what is taught in the most prestigious universities and colleges, gets published in the most prestigious journals, receives funds from the most important research foundations, and wins the most prestigious awards' (Dequech 2007-2008, p. 282), ideas that may be shared by others who are not in the elite circles. Orthodox economics can be defined as 'primarily an intellectual category ... as what historians of economic thought have classified as the most recent dominant "school of thought"' (Colander et al. 2004, p. 490). Dequech (2007-2008, p. 293) clarifies that although 'the reference to domination implies a sociological aspect, it is a particular set of ideas that defines a school of thought.' Although, like mainstream economics, its content can change over time, at any point in time it consists of a (reasonably) coherent set of ideas, ideas which are widely shared, and which, as a historical school, are slow to change. They are ideas that are taught, primarily through the more popular textbooks, at a large number of educational institutions - including the far less prestigious - and are popular among the large majority of those who have been taught some economics. The confusion among these different definitions arises from the fact that it is often argued that although the first definition - as an intellectual approach in terms of its characteristics - is the relevant one for defining neoclassical economics, the precise contents of mainstream economics and orthodox economics as they exist today also tell us about the content of that approach. This is clearly not the case, since in principle the three definitions of neoclassical economics are different, as the first one requires analytical judgment, the second requires an examination of what elite economists believe and do, and the third requires an examination of longer-lasting ideas shared widely. In practice one can distinguish between what is now mainstream economics and neoclassical economics, for instance by defining mainstream economics in terms only of what I will call methods of analysis and by defining neoclassical economics in terms of what I will call ontology and/or epistemology. For the purposes of this paper I will use the two terms, mainstream and neoclassical, interchangeably, and avoid using the term orthodox.

3. Some even question whether there is anything that exists now that can be called neoclassical economics. See, for instance, Colander (2000). I would argue that Colander's view is problematic because he seems to conflate what are some minority views of some leading economists who can be called mainstream economists with some characteristics of something coherent which can usefully described as neoclassical, as discussed below.

4. One can add also a theoretical dimension, which refers to specific theories, such as general equilibrium theory, the Heckscher-Ohlin theory, and Kaleckian theory. These theories, however, involve some of the other dimensions - for instance, the epistemological, ontological, and methodological dimensions. See Dutt (2014) for a fuller discussion.

5. In the Western philosophical tradition, the words epistemology and ontology are not always in these senses, since epistemology is sometimes defined as the study of the nature of and limitations of knowledge or the theory of knowledge, and ontology as the study of being, 
to the form in which the analysis is conducted and presented, and to the method by which the analysis is related to the empirical world to examine its relevance to the real world, or to understand specific real-world situations. The normative dimension refers to views on what is desirable, so that what happens in the world - or how the world is - can be evaluated in terms of whether, and to what extent, it leads to undesirable consequences and characteristics. Finally, the prescriptive dimension refers to what policies, strategies, and real-world interventions should be pursued. Although in principle these dimensions are autonomous and there is considerable independence on what dimensions can be and are chosen, the choices may not be independent in practice, since those made in one dimension may make those in other dimensions more likely among analysts, even if logical connections do not exist.

Although there are many differences in views and practices, many proponents of mainstream or neoclassical economics can be said to make the following choices in terms of these dimensions. Ontologically, individuals are seen as homo economicus that is, self-interested and consequentialist (in the sense that they are affected by what directly happens to them), materialist (in the sense of being interested mostly in material things or income), and insatiable (in the sense that they always prefer more of a good to less) - and the economy is organized in terms of markets which operate 'smoothly' (without 'distortions') through the price mechanism, generally to result in the full utilization of all resources. Epistemologically, behavior is viewed in terms of the optimizing agents who have objectives and beliefs about the consequences of their actions taking into account the constraints they face, and who make decisions to maximize their objective functions. This approach is not ontological because it says nothing specific about the constraints, objectives, and beliefs, so that, in principle, it can be used to address any views about the real world. In terms of methodology, the mainstream method emphasizes the use of mathematical models and econometric analysis, both involving increasingly sophisticated techniques. Normatively, the good society is one that is efficient, in the sense that it results in outcomes in which it is not possible to make anyone better off without making someone else worse off. Prescriptively, it recommends free markets and minimal government activity, other than to protect private property, enforce contracts, and defend the realm.

For many mainstream economists there is a certain unity in terms of the choices made in these dimensions. The optimizing agent, together with the assumptions about homo economicus and properly-functioning markets, can be shown to lead to efficient outcomes that are desirable (questions such as fairness are neglected because they are seen as involving non-scientific value judgments), so that minimal government intervention is called for. However, not every mainstream economist makes all these choices. For instance, a large number believe that there are many market 'imperfections' in the real world, such as those in the form of externalities, price-making behavior, and asymmetric information, and that there is therefore a need for government intervention. Some take the view that fairness is important in its own right, although it should be promoted without major sacrifices in terms of efficiency; some even argue that inequality and poverty are relevant for increasing efficiency.

existence, and reality. In the social sciences, a case can be made for epistemology to refer to what one means when one 'knows,' in terms of how one uses a common framework on analysis as an organizing principle, and for ontology to refer to statements about the real world. Epistemology can also refer to how one knows in relation to the real world, but I reserve the term 'empirical' dimension to that, to distinguish between organizing principles of analysis and relating analytical constructions to the real world, and will not discuss it here. 
In view of the fact that there are multiple dimensions to what we can call mainstream or neoclassical economics, it is very difficult to pin down who really can be characterized as being mainstream or neoclassical. For the purposes of this paper I will choose the dimension which is the most sympathetic and favorable to that approach - that is, the epistemological one involving the use of the optimizing agent. ${ }^{6}$ This approach uses, and insists on the use of, methodological individualism and the language of optimization. Epistemological approaches are neither right nor wrong, but can be more or less useful, given the purposes for which they are applied. Thus, I can concede that the approach is not fundamentally flawed, in contrast to what many heterodox economists argue.

However, even though the approach is not necessarily flawed, the choice of the optimizing individual as providing the epistemological approach increases the likelihood of some choices being made in other dimensions. I will focus here on the ontological dimension which, arguably, is the most important of the dimensions because it concerns what the world is like and - especially coupled with the normative dimension - has implications for the approach to policy. The optimizing framework requires the specification of the objective function of economic agents and the nature of the environment in which the agents operate. Although in principle the framework can incorporate virtually anything the analyst desires, to be useful it needs to be simple enough for the optimization procedure to produce definite results and for the resulting model to be analytically tractable. More specifically, to obtain definite behavioral results (which may or may not result in unique choices), the analysis is typically taken to be timeless, or, when time is involved, to assume complete certainty or objectively known or knowable probabilistic risk. Furthermore, to make the analysis tractable, the analysis focuses on a few aspects of social reality, such as markets which are either 'perfect' in the sense of functioning smoothly and without distortions, or have one or a few 'imperfections' - for instance, some externality, some sort of asymmetric information, or some form of market power. Thus, the epistemological approach leads to (although not out of logical necessity) specific ontological assumptions. This also tends to lead to some prescriptions about what has to be done in terms of policy. Since the individuals involved are 'rational' and clever, they have the ability to solve problems (when some 'distortions' exist) either by themselves or voluntarily with others. Moreover, since there are few problems (and often only one), these problems can be overcome by these individuals. The result is that even though 'distortions' present in a theoretical framework can result in inefficient social outcomes, modifications and extensions of the theory are often developed to show how individuals can overcome these problems. ${ }^{7}$ Failing that, the theory suggests that governments can quite easily 'solve' them with 'optimal' interventions, to achieve efficient outcomes.

6. Others have focused on different dimensions - for instance, the ontological dimension, which implies that markets clear and result in efficient outcomes, and the prescriptive dimension, which recommends free-market, neoliberal policies. Some have emphasized the methodological dimension concerning the use of mathematical models (see, for instance, Lawson 2013). I do not use these dimensions because, in the case of the ontological and prescriptive dimensions, many who call themselves neoclassical do not accept these characterizations, emphasizing, instead, the importance of market failures and advocating interventionist policies on these grounds and to promote fairness, and mathematical methods are neither necessary for, nor do they necessarily imply the use of, the optimizing approach, which I stress here.

7. There are many examples of this process, including those featuring efficiency wages (with workers posting bonds), externalities (by virtue of Coase's theorem), and the prisoners' dilemma (with infinitely repeated games with low rates of time preference). 


\section{UNCERTAINTY, POWER, AND INSTITUTIONS}

The ontological approach employed in most of mainstream economics, as described in the previous section, suffers from many weaknesses in terms of features of the real world that it emphasizes or neglects. Two concepts that can be argued to be of enormous importance for the real world are neglected by the mainstream approach, namely uncertainty and power, and one concept that has traditionally been neglected, but is now increasingly discussed in arguably problematic ways, is institutions. ${ }^{8}$

\subsection{Uncertainty}

It can be argued that most important economic (and other) decisions that have implications for the future are made in an uncertain environment, in which there is no objective basis upon which to assign probabilities as to their possible outcome. As Keynes (1937, pp. 213-214) pointed out in a frequently-cited passage:

By 'uncertain' knowledge, let me explain, I do not mean merely to distinguish what is known for certain from what is only probable. The game of roulette is not subject, in this sense, to uncertainty ... The sense in which I am using the term is that in which the prospect of a European war is uncertain, or the price of copper and the rate of interest twenty years hence ... About these matters there is no scientific basis on which to form any calculable probability whatsoever. We simply do not know.

In situations of uncertainty, decisionmakers: form expectations about the future with varying degree of confidence; follow various conventional patterns of behavior; attempt to maintain liquidity in an attempt to postpone decisions that are difficult to reverse; and make various types of arrangements attempting to reduce the uncertainty they face. Conventional patterns of behavior include: following the behavior of the majority; assuming that present trends will continue (unless there is very good reason to believe otherwise); and following the advice of so-called experts. Attempts to maintain liquidity can involve holding money or assets with short maturity periods and fixed yields, or, for firms, holding excess capacity in terms of physical capital. Arrangements with others include making long-term contracts - for instance, wage or employment contracts.

While what is called fundamental or radical uncertainty has been stressed in some strands of post-Keynesian economics (see, for instance, Davidson 1991; Dutt and Amadeo 1990), neoclassical economic analysis has not taken this into account and has instead conflated uncertainty with risk, for which there is an objective basis of forming probabilities from observing the world 'out there.' This has enabled it to develop axiomatic approaches to analysing behavior based on optimization, which can provide an unambiguous depiction of 'rationality. ${ }^{9}$ While this approach may be very sensible in some contexts, taking uncertainty seriously requires giving attention to how societies, and individuals and groups within them, try to cope with and reduce uncertainty, in ways that are likely to be context-dependent rather than being in the form of general laws based on an abstract axiomatic approach.

8. This section draws on Dutt (2014), which provides a fuller discussion.

9. Some mainstream analysis does try to distinguish between risk and uncertainty. See, for instance, Nishimura and Ozaki (2007), who assume that the decisionmaker takes into account different probability distribution to which he or she attaches different levels of confidence, and attempts to minimize the likelihood of bad events occurring. Still, the approach is developed axiomatically and seen as applying in all situations. 


\subsection{Power}

For many analysts, including Marx and his followers and the institutional economists such as Veblen (see Dugger 1980), power plays a fundamental role in the economy and in society. However, neoclassical economic analysis has traditionally had very little interest in the concept. It is missing from models with perfect competition with atomistic agents, on which the standard analysis of the market is based. It does make an entry in models of imperfect competition, in which market power exists only in the sense of the ability of some agents to determine or influence prices, and in game theory, in which the rules of the game can confer some advantage to players in non-cooperative games, and where bargaining power is parameterized in cooperative games with efficient bargains without any serious analysis of the sources of power. In neoclassical political economy it is often understood as arising from the ability to overcome collective action problems, as in the approach stressing the power of narrow interest groups (Olson 1965).

Power has sometimes been defined as the ability of some individuals to take decisions which make others act in ways that is against their interests and which they would not have otherwise taken. This definition, which is consistent with the analysis of, and is sometimes used by, neoclassical economists and so-called rationalchoice theorists who invoke the optimizing agent in other social sciences, is limited in scope. This is because it ignores the use of power to dominate others by selecting issues to be considered in negotiations, and the possibility that the preferences and values of people result from social processes and can be influenced by the powerful to their perceived advantage, so that the dominated acquiesce to their domination (see Lukes 2005). To be sure, the definition can be broadened and used within the optimizing approach to take into account purposive action to change the 'rules of the game' (or what can be called 'structure') and to change the preferences of other individuals. ${ }^{10}$ However, the optimizing approach, with intentional behavior, can be criticized for producing a narrow notion of power, both because it confines attention to intentional actions in the context of relations between the more and less powerful, and because it does not provide, and arguably does not lend itself to, an analysis of the complex and multiple sources power. Other approaches that do not start from the individual optimizing agent provide a richer perspective, for instance by invoking the notion of structural power, which is distinguished from relational power that is exercised in the interaction between two or more individuals or groups, and which, while taking into account intentional actions by people and groups to influence the structures within which society operates, recognizes that these structural outcomes may be unintended or unconscious (see, for instance, Strange 1988 and Guzzini 1993, in the context of international relations). Moreover, such an approach can examine different spheres of power, such as in production activity, control over finance, control through violence, and control over knowledge and culture (see Strange 1988). Power in these different spheres can have complicated, unintended, and often self-reinforcing relations between each other, and cannot be reduced simply to the relations between individuals or even between groups.

10. Bartlett (1989, p. 30), for instance, presents a rare attempt to use the optimizing approach to explore power in economics using a generalization of the definition in contexts in which there is imperfect information, organizations involving rules such as the employment relation, and endogenous preferences which can be controlled. 


\subsection{Institutions}

The concept of institutions, which has been defined loosely as the 'rules of the game' (North 1990), can be seen for the purposes of this paper to refer to: first, more or less codified constitutions, laws, and regulations; second, collections of shared norms and habits that garner wide acceptance; and, third, formal and informal organizations such as government bureaucracies, firms, markets, and families (see, for instance, Hodgson 2006). This three-pronged view of institutions is useful because the operation and effects of any particular institution cannot be fully understood without invoking the three aspects. ${ }^{11}$

The role of institutions in the economy, long ignored by neoclassical economists (for instance by ignoring how property rights and contracts are enforced in the general equilibrium theory of markets), but emphasized by the institutionalists (such as Veblen and Commons, now called 'old' institutionalist economists), has for several years been receiving a great deal of attention from 'new' institutionalist economists. These economists, who generally use the neoclassical homo economicus approach, emphasize the importance of transactions costs. These costs can result in inefficiencies in markets even if individuals are optimizers, and institutions are necessary to reduce these transactions costs and increase efficiency in the standard economists' sense (North 1990). They also take into account the fact that all economic interactions do not take place in markets, but also in organizations that involve hierarchical structures, as they may be better at reducing transactions costs than markets (Williamson 1985). Although some 'new' institutionalist economists do point out that the actions of individuals in society may not lead to efficiency-improving institutional changes, they generally take the view that it is possible to identify good institutions that reduce transactions costs and promote the efficient operation of free markets and capitalist societies, and recommend their adoption. A view has gained wide currency that there is a desirable set of institutions that must be established, including those that establish secure private property rights and that increase the smooth operation of markets, for instance by removing restrictions on firing workers in labor markets; and a relatively large empirical literature, using cross-country regressions, has emerged purporting to show that 'better' institutions result in higher growth.

Although the neoclassical approach to institutions focusing on individual optimizing behavior can be seen as an improvement on the standard neoclassical approach that ignores the role of institutions by assuming away transactions costs and examines smoothly functioning markets (see North 1994), it is problematic for a number of reasons. First, the concept of transactions costs, which can refer to anything that is ignored in smoothly-functioning markets as a theoretical construction, is arguably too vague to properly identify specific real-world institutions. Second, the goal of efficiency is impossible to operationalize without having a precise knowledge about people's utility functions, is problematic to define if preferences are endogenous (as North 1994 allows), and arguably is not the only or even the most important goal for society, as it ignores other goals such as fairness, functionings and capabilities, and reducing vulnerability and insecurity, especially that of the poor. Third, the analysis of institutional change involving the optimizing approach focuses on some issues, like those emphasized in Olson's (1965) theory of collective action, and does not take into

11. For instance, the institution of private property rights requires laws, norms which affect the extent to which such property rights will be respected, and organizations, such as the police and the judiciary, to enforce. 
account unintentional forces which affect institutional changes involving all three of its dimensions.

\subsection{Interrelations}

Not only are the three concepts just discussed of great importance and not adequately treated in mainstream economics, they are closely interrelated.

One of the ways in which people and groups try to react to uncertainty is by developing institutions - legal frameworks, shared behavioral rules and norms, or organizational arrangements - which seek to reduce it or to help them cope with it. North (2005), who earlier stressed the role of institutions in reducing transactions costs, has recently shifted his emphasis to how institutions attempt to address the problem of uncertainty. The existence of uncertainty also allows power to emerge, to be exercised, and to be contested. Uncertainty about the future implies that people may base their expectations of the future on expert opinions or what market leaders are doing or more broadly interpret the world relevant for them and its future in terms of lenses and values which can be affected by those who can disproportionately affect the media, academia, and the general education system, which provides some people with information and financial power. Without uncertainty, information would be easier to come by, although it could still be controlled by some to exercise their power; uncertainty increases this ability. Moreover, the existence of uncertainty implies that the relatively weak can contest power, propelled by buoyant animal spirits, which they might not if they could calculate objective probabilities to find that they are likely to lose.

Power has implications for both uncertainty and institutions. The effect of power struggles adds to uncertainty, since the outcomes of contestations differ from case to case, and many unknowable factors enter into such conflicts. The interaction of powerless 'atoms' is more likely to result in probabilistically knowable future consequences rather than in what Keynes referred to as the organic rather than the atomic view of society. Power allows some groups to develop and modify institutions in the form of laws and organizations, given their ability to influence public opinion and their ability to affect government behavior, and influence norms, given the advantage they possess in sanctioning deviations from the norms and their denser connections with others.

Finally, institutions have implications for uncertainty and power. Institutions, because they are often intended to reduce uncertainty, can sometimes indeed do so. For instance, explicit or implicit long-term wage contracts can result in nominal wage rigidity, which can reduce uncertainty for both workers, who can be assured of their incomes during the term of the contract, and for firms, for whom wage can be a large part of costs. Sometimes institutional arrangements that are intended for other purposes - for instance, wage bargaining processes involving unions and firms, or more centralized bargaining agreements - can also make wages rigid, and thereby reduce uncertainty. However, some institutions can also increase uncertainty. For instance, norms used by decisionmakers to follow others lead to herding behavior in asset markets and for investment behavior by firms, which can result in bubbles and instability, thereby increasing uncertainty. The nature of institutions involving organizations like firms with specific employment relations and involving behavioral rules which give great weight to expert opinion provides power to some groups and people, such as employers and experts and those who can influence them. Institutional arrangements can not only reflect power relations, but also reify and reinforce them: institutions reflecting the interests of powerful groups 
often produce outcomes favorable to them, which increase their power. However, institutions in the form of laws and regulations can possibly also limit the ability of some people and groups to exert power over those who are less powerful by giving the latter some legal and regulatory protections.

\subsection{Uncertainty, power, institutions, and the crisis}

The relevance of the three interrelated concepts discussed in this section to the crisis is reasonably straightforward and can be very briefly mentioned.

Uncertainty, especially in asset markets, leads to financial instability unless financial actors are regulated. Uncertainty also leads households and firms to increase spending, financed partly by increased borrowing when they expect the future to be rosy, and to reduce consumption and especially investment to low levels when the future seems bleak to them, and to possibly not responding to government efforts to increase their spending through expansionary monetary policy and even fiscal policy, especially tax cuts. The expansion of government spending can increase aggregate demand, but can have low multiplier effects in pessimistic times, both because firms may be wary about increasing employment and investment, and because households are more likely to repay debts than increase spending.

The power of financial interests leads them, through their influence on academia and the government, to promote financial deregulation and to block efforts to regulate new financial instruments. The power of the rich, again through their influence on the government and academia and the media, also leads to policies which provide tax breaks to the rich and otherwise reduce regulations which try to contain inequality. The power of the US and other countries in relation to the poor countries allows them to have a strong influence in international organizations and by themselves - through bilateral regulations with less-developed countries, by offering them foreign aid and market access - tilt the rules and practices of the global economy in their favor, by promoting neoliberal policies and conditions around the globe. The policies and conditions include freer trade, freer capital flows, the protection of intellectual property rights, and an international monetary system in which the dollar dominates as the international currency and poor countries are exposed to international financial uncertainty and volatility, and increases in the power of transnational corporations. These changes in policies and domestic and international institutions in turn shift the distribution of income within and between countries generally towards rich people and rich countries. Poor countries, however, need not be doomed to stagnation. Some of them can experience high rates of growth, sometimes - as in the cases of South Korea and Taiwan - with the help of rich countries in the form of financial assistance and market access, often for geopolitical reasons, and sometimes - especially in the case of larger countries like China and India - through the use of pragmatic policies which depart from the standard neoliberal approach.

\section{IMPLICATIONS FOR ECONOMIC ANALYSIS AND POLICY AND THE FUTURE OF CAPITALISM}

The proper conceptualization and analyses of uncertainty, power, and institutions has major implications for the nature of economic analysis and policy and the future of capitalism. A thorough examination of these implications is beyond the scope of this paper. Instead, I will make some brief remarks on three broad interrelated issues 
regarding the future of capitalist economies and their relevance to policy debates, and discuss how they follow from the implications of the three concepts for the different dimensions of economic analysis discussed earlier.

\subsection{The state and markets}

A popular dichotomy in economic analysis and policy discussions is between the markets and the state. Based on this dichotomy, many argue that markets without government restrictions are desirable, while others argue in favor of government intervention in the economy. These opposing views have been justified on a variety of grounds, with appeals to their implications for efficiency, fairness, growth, freedom, and justice, sometimes with different meanings attached to these concepts. The debate used to be couched in terms of the desirability of alternative economic systems, the extreme alternatives being capitalism and socialism, terms which have a variety of meanings as well. The end of the Cold War seems to have put the proponents of state intervention on the defensive, with the market system as the last system standing (with some even proclaiming the end of history in the sense that the perfect system has been found), but the debates continue to be posed in much the same way as before. Basically, in terms of policies, the former approach has been associated with policy prescriptions (which, incidentally, often require strong state intervention), involving the deregulation of markets, privatization of government-owned enterprises, and external liberalization aimed at reducing trade barriers and barriers to international capital flows, the latter approach involving more state ownership and direction of the economy and less reliance on free market forces to determine the distribution of income and wealth.

There are many problems with this approach to the examination of the state and markets. Without discussing them in detail, I examine the issue in terms of the three concepts emphasized in this paper.

First, once the market and the state (and its components) are viewed as institutions, the distinctions between the two become blurred. As institutions, markets are intrinsically connected with laws and regulations, social norms, and organizations that are required for their functioning and their very existence. The market requires the state and organizations within it to enforce contracts and prevent criminal activity (such as those that create insecurity regarding property rights), and to prevent the erosion of social norms that can be weakened or destroyed by some of the excesses resulting from market activity. These norms, such as those that promote trust and cooperation, are required for the smooth operation of markets by providing markets with appropriate social underpinnings (see, for instance, Smith 1776 [1961]; Granovetter 1985; Greif 1997). Moreover, through legislation and by affecting norms, the state can avoid social upheavals which can undermine the social fabric that holds the market system together (Polanyi 1944). The state also involves markets and private individuals operating them in various ways, for instance, for raising revenue from market activity through taxation, ensuring compliance by using markets as disciplining devices, by using market-like arrangements to conduct government programs, and because the state simply cannot do everything to achieve the outcomes it desires, and has to obtain the cooperation of market participants.

Second, recognition of the importance of uncertainty has important implications for the functioning of capitalist economies, as has been recognized by Keynes and the post-Keynesian economists for a long time. The presence of uncertainty implies that decisionmakers follow various types of behavioral rules, for instance markup pricing 
and investment decisions that are based on the current state of the market as measured by profits and capacity utilization, and form institutions which lead to wage and distributional rigidities. As has been demonstrated in a variety of models that incorporate these behavioral and institutional assumptions, output, employment, and growth in the economy are affected by aggregate demand both in what can be called the short run and in the long run. These models imply that economies can be and usually are characterized by persistent unemployment and excess capacity, and are likely to be affected by endogenously generated financial crises that have adverse effects on the real economy. Given all these problems, the state can improve the functioning of markets by reducing unemployment, reducing instability, and raising the rate of economic growth, when desired, through activist fiscal, monetary, and other policies. Even if individuals in markets have more access to localized knowledge under some circumstances, in the presence of uncertainty, when macroeconomic factors affect individual decisionmakers and the effects of these decisions, the state can help in using macroeconomic information and coordinating the activities of individuals and groups.

All of this is not to say, of course, that the state can always solve all the problems resulting from uncertainty. For instance, the volatility of government policies can conceivably increase uncertainty in the economy, and government policies may not always work precisely as desired because of the role of, and the difficulty of influencing, expectations. These problems do not, however, reverse the basic point that the withdrawal of the state from the economy does not unequivocally lead to improvements. What they imply is that the expectations regarding the success of government policies should not be too high, and that governments should try to avoid haphazard changes in policies. ${ }^{12}$

Taking into account the importance of power also has implications for the relative effectiveness of the state and markets. Power can be exercised in both markets and state institutions, in the former by affecting prices and hence distributional outcomes and in the latter through the selection and implementation of policies. Moreover, power in one sphere affects power in the other: for instance, increases in the share of income of a group in the market sphere can increase the ability of influencing government policies, and particular policies can influence income distribution as determined by markets. It can happen, as it did before the financial crisis, that the nature of government policies may be influenced by powerful groups whose interests may be antithetical to societal improvements. Despite this, it is more likely that in many societies there is greater scope for the state to do more to curtail the power of the more powerful, especially in democracies that give more voice to the less powerful and because of the power of ideas rather than vested interests, and produce positive social and economic processes and outcomes, even though social movements and organizations such as labor unions can also affect markets and the private sphere. But even for the latter, the government is in a position to influence their power to affect market outcomes.

\subsection{Fairness and income distribution}

It has been observed by many commentators that the level of income and wealth inequality has followed an upward trend in many countries, both rich and poor, and by some

12. This does not imply that the government should follow rules rather than use its discretion, or follow simple rules like having a constant money supply growth rate or a targeted inflation rate. Rather, it implies that the government should avoid haphazard changes in policy. Since we have uncertainty rather than risk, and since markets do not clear, the policy ineffectiveness result does not follow from the pursuit of systematic policies! 
measures inequality between countries has been on the rise. For the sake of brevity I will confine my attention to domestic inequality; broadly similar arguments apply to the international sphere. My analysis implies that there is a need for capitalist societies to pay greater attention to income distribution and inequality in order to reverse the trend towards rising inequality. The case for this can be made on the basis of at least two separate arguments.

First, my analysis strengthens the normative case for greater equality. Even if there are grounds for accepting the egalitarian view that great equality - in terms of things that matter, such as resources, income, and capabilities - is intrinsically desirable, legitimate objections can be made against it with the argument that inequality based on what has been called the desert perspective (that is, as a reward for effort and choices), or from the perspective that it is based on voluntary choices, is justifiable. Regarding the desert view, some analysts have argued that individuals can experience unequal outcomes as a result of a variety of causes, including choices they make, the effort they exert, luck, and birth. Many accept that to the extent that birth confers advantages to some and disadvantages to others, there is a need for equalization. Many, but perhaps a smaller number, accept that inequality based on luck, if its consequences are unavoidable (for instance, through the purchase of insurance), also needs to be reduced. However, a large number argue that inequality resulting from good choices and high levels of effort is justified and should not be reduced through redistributive policies. The recognition of the importance of uncertainty implies that outcomes regarding the returns to choices made and efforts exerted are uncertain, and not systematically related to the 'correctness' of choices or the intensity of effort, so that the justification of actual returns in terms of rewards is considerably weakened. Moreover, to the extent that asymmetries in power, and the nature of institutions reflecting them, systematically skew outcomes to favor the more powerful, the argument against redistribution based on desert or voluntary actions is also weakened.

Second, taking into account these concepts has implications for income distribution because of how it affects other desirable goals, such as growth, reducing unemployment, and stability. Taking into account uncertainty, as noted earlier, implies that the economy can be seen as being in short-run and long-run equilibrium with unemployment and excess capacity (see Dutt 1984; 1990; Rowthorn 1982). In models of this kind, it has been found that a redistribution of income towards groups with a higher propensity to consume - such as wage recipients and lower-income groups increases consumption demand and hence aggregate demand and capacity utilization. Although it is possible that a fall in the share of income going to profits can reduce investment, the outcome investment spending is driven largely by expectational factors (see Bhaduri and Marglin 1990): if firms expect capacity utilization to increase sufficiently in future because they observe current increases in it, they are likely to increase investment spending and thereby increase the rate of capital accumulation. In open economies, increases in wages can erode export competitiveness, but this is not a necessary outcome if higher wages result in higher labor productivity, and if exports are affected by non-price factors connected with product quality.

The distribution of income between wages income going to workers and profit income going to capitalists is not the only determinant of the overall distribution of income. We also need to take into account the income going to financial classes, managers, and highskilled workers. The distribution of income involving these groups can be used to explain empirical trends in many countries and also to examine the effects on aggregate demand and growth in an uncertain environment with unemployment and excess capacity.

Moreover, the distribution of income is relevant for the performance of the economy not only by affecting aggregate demand directly, but also via other channels, 
including those operating through financial markets. Rising inequality can lead to an increase in borrowing by groups for which income has stagnated and lending by groups for which income has increased. The rise in borrowing and debt creation, as well as the liquidity in asset markets, can result in financial instability due to changes in confidence interacting with debt and asset prices. Rising inequality also affects the balance of power between different groups in society, which can - as noted earlier have enormous consequences on the nature of policies and market outcomes.

\subsection{Market flexibility}

A third aspect of capitalist economies which has frequently been emphasized is the need for increasing flexibility in the operation of markets. For instance, it is argued that labor market inflexibility in the form of wage rigidity slows down labor market adjustment to shocks and results in the persistence of unemployment, and that in the form of employment rigidity slows down employment growth because of the difficulties prospective employers think they will face in reversing their decisions and laying off workers when they do not need them. Regarding the financial sector, it has been argued that rigidities have resulted in financial 'repression,' which has resulted in reducing the overall flow of finance and has stood in the way of financial 'deepening,' leading to an inefficient allocation of finance, especially in less-developed countries. Very often these 'rigidities' are blamed on government regulations, such as minimum wage laws, restrictions on hiring and firing, capital adequacy requirements for banks, restrictions on interest rate movements, and government oversight of banks and other financial investment companies and new financial instruments. Thus, the push for greater market flexibility is often seen as an aspect of reducing the role of the state in the economy. However, sometimes the calls for greater market flexibility are seen as requiring the active intervention of the state to promote flexibility, for instance by changing institutions that are developed by market participants, in some cases by changing power relations within markets, such as the power of labor unions.

The arguments favoring market flexibility do not take proper note of markets as institutions that embody characteristics to cope with, and reduce, uncertainty. Without the so-called rigidities, markets can become unstable, increasing the vulnerability of people, and induce people and groups to react to uncertainty in ways that can lead to poor economic outcomes. Consider, for instance, employment and wage rigidity. For workers, wages from employment are the major, if not the only, source of income and for firms wage payments comprise a major element of variable costs. Wage and employment flexibility implies that the future becomes more uncertain for workers and firms, and can lead to decreases in consumption and investment spending as they increase their saving and try to become more liquid. The wage-price deflation that can follow can lead to problems of debt deflation which spills into financial markets. Financial deregulation has been shown to increase financial instability as lenders and borrowers expand lending and borrowing when they are optimistic, which leads to asset bubbles and the realization of over-indebtedness, which leads to pessimism and financial collapse. The result is a credit freeze that reduces investment, consumption, output, and employment.

Individuals and groups are often aware of the positive effects of these rigidities and attempt to introduce them individually or collectively. For instance, long-term wage agreements can be made by workers and firms to reduce uncertainty for both sides, and also as a form of gift exchange, in which firms pay workers more than what can be called marketclearing wages in return for their loyalty (Akerlof 1982). Financial institutions also try 
to be prudent by keeping enough reserves and liquid assets on hand. However, in an uncertain situation, people and groups are unlikely to find the right balance, and it is likely that they will make persistent mistakes: firms are likely to be more concerned with actual wage costs rather than the potential and uncertain increases in productivity due to higher wages, and lenders are more likely to be euphoric when they see their competitors taking risks. Moreover, many of these effects involve the actions of a large number of people and groups: uncertainty is increased not because one or a few make the wage more flexible, but because many do. Government regulations and requirements, in this situation, provide an anchor to which private market participants can attach themselves. Removing the anchor is likely to result in uncertainty, instability, and poor outcomes. A further effect of reducing rigidities is that the influence of the more powerful in affecting outcomes, for instance in reducing wages and in expanding indebtedness for financial gain, not only has adverse effects on income distribution and economic activity as discussed earlier, but also hurts many of the powerful individuals and groups who successfully try to push outcomes with the mistaken belief that they will favor them, falling prey to the fallacy of composition.

\section{CONCLUSION}

This paper has argued that three features of capitalist economies - uncertainty, power, and institutions - are important for understanding the nature and performance of modern capitalist economies in general and for understanding the global financial crisis in particular. Mainstream neoclassical economic analysis, with the individual optimizing agents as its starting point, has not taken these issues into account, at least in an adequate manner, and the result has been a tendency to support neoliberal policies with free markets and limited state intervention. Properly taking these aspects of the real world into account suggests that: the market and the state should not be seen as alternatives; the extent and nature of the role of the government in the economy depends on the economic, political, and social context; there should be a stronger focus on reducing inequality; and increasing market flexibility can have destructive consequences for the economy and society.

These implications are not new, and have been made by many critics of neoclassical economics and neoliberal policies. If the paper has any claims to novelty, it is in pointing out how neoclassical economic analysis has gone wrong in not dealing adequately with the enormous role of uncertainty, power, and institutions, and their interaction in the economy and society, and how this has biased its prescriptions towards neoliberal policies, and in suggesting why the state needs to have a significant role in the economy. I end with three concluding comments.

First, this paper has not developed an approach that can be an alternative to the neoclassical one in terms of its epistemological dimension. Is the neoclassical approach the only game in town, as many of its proponents claim? There clearly are alternatives, including the approaches used in some of the contributions referred to in the previous section. I have elsewhere argued that a strong case can be made for an alternative approach that starts with accounting relations between relevant variables (which may be flow variables, stock variables, and relations involving both stocks and flow variables); uses behavioral and institutional relations between the different variables to 'close' the system in order to 'solve' the model; and chooses these relations on empirical grounds (which may involve formal econometrics, broader historical analysis, and detailed case studies) from various theoretical traditions in economics and outside it, 
taking into account the motives and behavior of individuals and groups (see Dutt 2003; Taylor 2004). The approach does not have to be mathematical, and sometimes should not be, as some of the relations between variables may not be systematic or law-like. Moreover, the analysis should not be thought of as providing precise depictions of reality (which it cannot, given the importance of uncertainty) but as providing qualitative 'stories' about the main forces at work in an economy and society. ${ }^{13}$

Second, although it has pointed in the direction of a general policy perspective, this paper has not provided any specific policy proposals. Taking its implications seriously, in fact, implies that there are no specific proposals that can be made which are relevant for all times and places. It suggests that appropriate policies should be based on careful knowledge of the nature of institutions and power relations of a context, without the blinkers that come from insisting that the world can only be understood in terms of neoclassical optimizing agents and allowing for insights to be drawn from alternative approaches such as the one just mentioned. Policies should be chosen after broad public deliberation and discussion (not just the advice of so-called experts), and allow for experimentation and diversity (rather than dogmatic allegiance to a single approach). ${ }^{14}$

Third, is a change away from the dominance of the free market approach possible? Clearly, there are many constraints that prevent change, including the power of vested interests and dominant groups and classes in affecting public policy, the role of neoliberal intellectuals in general (who are not necessarily dependent on neoclassical economic theory for a justification of their views), and the nature of the economics academy in which many people support the mainstream approach out of self-interest and inertia rather than for intellectual reasons. However, there are signs of political change in some parts of the world. Moreover, the power of ideas should not be underestimated. Keynes was probably only exaggerating a little when he ended his General Theory with the words:

The ideas of economists and political philosophers, both when they are right and when they are wrong, are more powerful than is commonly believed. Indeed, the world is ruled by little else. Practical men, who believe themselves to be quite exempt from any intellectual influences, are usually the slaves of some defunct economist. Madmen in authority, who hear voices in the air, are distilling their frenzy from some academic scribbler of a few years back. I am sure that the power of vested interests is vastly exaggerated compared with the gradual encroachment of ideas. Soon or late, it is ideas, not vested interests, which are dangerous for good or evil. (Keynes 1936, pp. 383-384).

13. As this approach does not commit itself to particular 'closures' but to the method of closing the accounting identities by using additional relations that capture what are considered to be important aspects of reality, it is an epistemological approach. The approach is not really new, but draws on a variety of approaches and does not base itself on the neoclassical approach using the optimizing agent (though is not inconsistent with it), including many writings in the postKeynesian, classical Marxian, old Keynesian, institutional, and behavioral traditions, not to mention some neoclassical approaches (in terms of ontology). See Dutt (1990) for an example of the use of this approach.

14. The title of this paper refers to the future of capitalism. This term is employed because of its widespread use to describe a system in which individuals and groups make many decisions affecting their lives for themselves, and where institutional arrangements, including markets, are largely the result of voluntary decisions of individuals and groups. The usage of this term places no a priori restrictions on the nature and extent of state intervention or ownership on the economy, provided it is not all-encompassing. Clearly, capitalism can be of various types, as is suggested in the literature on various types of capitalisms, such as Esping-Anderson (1990) and Hall and Soskice (2001), which provide typologies that can prove helpful in choosing particular combinations of policies. 


\section{REFERENCES}

Akerlof, George A. (1982), 'Labor contracts as partial gift exchange,' Quarterly Journal of Economics, 97(4), 543-569.

Bartlett, Randall (1989), Economics and Power: An Inquiry into Human Relations and Markets, Cambridge, UK: Cambridge University Press.

Bhaduri, Amit and Marglin, Stephen A. (1990), 'Unemployment and the real wage: the economic basis for contesting political ideologies,' Cambridge Journal of Economics, 14, 375-393.

Colander, David (2000), 'The death of neoclassical economics,' Journal of the History of Economic Thought, 22(2), 127-143.

Colander, David, Holt, Rick P., and Rosser Jr., J. Barkley (2004), 'The changing face of mainstream economics,' Review of Political Economy, 16(4), 485-499.

Davidson, Paul (1991), 'Is probability theory relevant for uncertainty? A post Keynesian perspective,' Journal of Economic Perspectives, 5(1), 129-143.

Dequech, David (2007-2008), 'Neoclassical, mainstream, orthodox and heterodox economics,' Journal of Post Keynesian Economics, 30(2), 279-302.

Dugger, William M. (1980), 'Power: an institutional framework of analysis,' Journal of Economic Issues, 14(4), 897-907.

Dutt, Amitava Krishna (1984), 'Stagnation, income distribution and monopoly power,' Cambridge Journal of Economics, 10(1), 25-40.

Dutt, Amitava Krishna (1990), Growth, Distribution and Uneven Development, Cambridge, UK: Cambridge University Press.

Dutt, Amitava Krishna (2003), 'On Post Walrasian economics, macroeconomic policy and heterodox economics,' International Journal of Political Economy, 33(2), 47-67.

Dutt, Amitava Krishna (2014), 'Dimensions of pluralism in economics,' Review of Political Economy, 26(4), 479-494.

Dutt, Amitava K. and Amadeo, Edward J. (1990), Keynes's Third Alternative? The Neo-Ricardian Keynesians and the Post Keynesians, Aldershot, UK: Edward Elgar.

Esping-Andersen, Gosta (1990), The Three Worlds of Welfare Capitalism, Princeton, NJ: Princeton University Press.

Granovetter, Mark (1985), 'Economic action and social structure: the problem of embeddedness,' American Journal of Sociology, 91(3), 481-510.

Greif, Avner (1997), 'Contracting, enforcement and efficiency: economics beyond the law,' in M. Bruno and B. Pleskovic (eds), Proceedings of the World Bank Annual Conference on Development Economics, 1996, Washington, DC: The World Bank, pp. 239-265.

Guzzini, Stefano (1993), 'Structural power: the limits of neorealist power analysis,' International Organization, 47(3), 443-478.

Hall, Peter A. and Soskice, David W. (eds) (2001), Varieties of Capitalism: The Institutional Foundations of Comparative Advantage, Oxford: Oxford University Press.

Hodgson, Geoff (2006), 'What are institutions?' Journal of Economic Issues, 40(1), 1-25.

Keynes, John Maynard (1936), The General Theory of Employment, Interest and Money, London: Macmillan.

Keynes, John Maynard (1937), 'The general theory of employment,' Quarterly Journal of Economics, 51(2), 209-223.

Lawson, Tony (2013), 'What is this "school” called neoclassical economics?' Cambridge Journal of Economics, 37, 947-983.

Lukes, Steve (2005), Power: A Radical View, 2nd edn, Basingstoke: Palgrave Macmillan.

Minsky, Hyman (1982), Can 'It' Happen Again? Essays on Instability and Finance, Armonk, NY: M.E. Sharpe.

Mirowski, Philip (2013), Never Let a Serious Crisis Go to Waste, London: Verso.

Nishimura, Kiyohiko G. and Ozaki, Hiroyuki (2007), 'Irreversible investment and Knightian uncertainty,' Journal of Economic Theory, 136, 668-694.

North, Douglass C. (1990), Institutions, Institutional Change and Economic Performance, Cambridge, UK: Cambridge University Press. 
28 Review of Keynesian Economics, Vol. 3 No. 1

North, Douglass C. (1994), 'Economic performance through time,' American Economic Review, 84(3), 359-368.

North, Douglass C. (2005), Understanding the Process of Economic Change, Princeton, NJ: Princeton University Press.

Olson, Mancur (1965), The Logic of Collective Action, Cambridge, MA: Harvard University Press.

Polanyi, Karl (1944), The Great Transformation, New York: Reinhart.

Rowthorn, Robert (1982), 'Demand, real wages and growth,' Studi Economici, 18, 3-54.

Smith, Adam (1776 [1961]), An Inquiry into the Nature and Causes of the Wealth of Nations, Edwin Cannan (ed.), London: Methuen.

Strange, Susan (1988), States and Markets: An Introduction to International Political Economy, Oxford: Basil Blackwell.

Taylor, Lance (2004), Reconstructing Macroeconomics: Structuralist Proposals and Critiques of the Mainstream. Cambridge, MA: Harvard University Press.

Williamson, Oliver E. (1985), The Economic Institutions of Capitalism, New York: Free Press. 